\title{
Evaluation of Aroma Generation of Lactococcus lactis with an Electronic Nose and Sensory Analysis
}

\author{
N. Gutiérrez-Méndez, ${ }^{\star}$ B. Vallejo-Cordoba, ${ }^{\star 1}$ A. F. González-Córdova, ${ }^{\star}$ G. V. Nevárez-Moorillón,† \\ and B. Rivera-Chavira† \\ ${ }^{*}$ Centro de Investigación en Alimentación y Desarrollo A.C. (CIAD, A.C.). Carretera a la Victoria Km. 0.6, Hermosillo, Sonora, 83000, México \\ †Facultad de Ciencias Químicas, Universidad Autónoma de Chihuahua. Apartado Postal 1542-C, Chihuahua, Chihuahua, 31170, México
}

\begin{abstract}
There is an increased interest in exploring the potential of new Lactococcus lactis strains isolated from different natural ecosystems for the production of aroma compounds. Thus, the objective of this study was to screen the aroma generation of Lactococcus lactis strains isolated from different sources by an electronic nose and sensory evaluation for their potential use in starter cheese cultures. Twenty-three strains of Lactococcus lactis were isolated from dairy sources such as artisanal raw-milk cheeses, nondairy sources, and commercial starter cultures (industrial). All the strains were assessed for their ability to produce aromas by an electronic nose and sensory analysis after their incubation in milk. Some phenotypic characteristics of technological importance such as lactose fermentation, proteolytic activity, and citrate utilization were also evaluated. Lactococcus lactis strains showed clear phenotypic differences related to their isolation source. Strains isolated from raw-milk dairy products or commercial starter cultures presented faster lactose fermentation and proteolytic activity than those presented by strains isolated from nondairy sources. Additionally, strains isolated from dairy and nondairy sources presented better citrate utilization than strains isolated from commercial dairy starters. On the other hand, there was not a clear relationship between the source of isolation and the ability of lactococci strains to produce aroma. Principal components analysis of electronic nose data revealed 4 distinctive groups based on aroma profiles. Additionally, odor intensity scores (yogurt-like and Fresco cheese-like) for these 4 groups revealed the nature of their differences. In general, strains from dairy products presented intense yogurt-like and Fresco cheese-like aromas, with the latter being the most intense for one specific strain. On the other hand, the
\end{abstract}

Received March 13, 2007.

Accepted October 16, 2007.

${ }^{1}$ Corresponding author: vallejo@cascabel.ciad.mx majority of wild strains from nondairy sources presented a stronger yogurt-like aroma, whereas industrial strains presented low intensity for both aroma descriptors. Additionally, an aroma potentiation effect was observed when mixtures of 2 lactococci strains isolated from different sources acted together.

Key words: aroma, electronic nose, Lactococcus

\section{INTRODUCTION}

Flavor compounds in cheese are the result of lactose, citrate, fat (lipolysis), and casein (proteolysis) conversion by enzymatic reactions (Van Kranenburg et al., 2002), although there are also some nonenzymatic reactions (Smit et al., 2004). The starter lactic acid bacteria (LAB) and the nonstarter LAB are the main source of enzymes involved in these pathways (Smit et al., 2005), and Lactococcus lactis are the most used LAB in the production of cheese and other fermented dairy products (Salama et al., 1993). Lactococcus lactis have a complex proteolytic system that together with other proteolytic enzymes convert casein into peptides and amino acids (Law and Haandrikman, 1997). The amino acids are the key precursors of volatile flavor compounds, once they are metabolized to aldehydes, ketones, amides, alcohols, and sulphur compounds (Yvon and Rijnen, 2001; Smit et al., 2005).

Lactococcus lactis are widely spread in nature (Stark and Sherman, 1935; Salama et al., 1993; Salama et al., 1995; Klijn et al., 1995, Corroler et al., 1998), and recently, there is an increased interest in exploring the potential of new strains isolated from different natural ecosystems for the production of aroma compounds (Ayad et al., 2002). In fact, there are several reports on the isolation of indigenous LAB from different types of Spanish artisanal cheeses with the goal of selecting specific strains for making industrialized cheese from pasteurized milk to ensure a similar flavor to that of artisanal cheese made from raw milk (Perez-Elortondo et al., 1998; Centeno et al., 1996; Estepar et al., 1999; Herreros et al., 2003, 2007). 
In our laboratory, the natural microflora of Mexican Fresco cheese was characterized as a first step toward the development of starter cultures, which would allow the making of a safe and uniform product from pasteurized milk (Torres-Llanez et al., 2006). The results in this study suggested that an adequate starter for flavor production in Mexican Fresco cheese from pasteurized milk may be made by the dominating isolates, which were characterized as being Lactococcus lactis ssp. lactis, Lactobacillus casei, and Enterococcus faecium (Torres-Llanez et al., 2006).

Additionally, the flavor generation ability of lactococci isolated from nondairy sources was also evaluated (Ayad et al., 1999, 2000, 2001). Analysis of volatile compounds by gas chromatography showed that some lactococci isolated from nondairy sources produced higher levels of specific aldehydes than strains isolated from commercial cultures (Ayad et al., 1999, 2000, 2001; Centeno et al., 2002). However, despite these promising findings, it is necessary to assess if the increase of these volatiles produced a significant change in overall aroma. The balance of aroma components determines largely the sensory quality of dairy products, and an increase of only a few flavor compounds could produce an unbalanced aroma or imperceptible changes of aroma (Smit et al., 2005).

An objective method for the study of overall food aroma evaluation is the use of electronic noses (Deisingh et al., 2004). However, the electronic nose offers an additional technique for analyzing aroma and is complementary to sensory analysis and GC-MS (Hodgins, 1997). The main difference between the human and the electronic nose is that the latter cannot define what the complex aroma is or whether it is acceptable to the human. This information needs to be obtained from a human, and therefore the electronic nose can only be complementary (Hodgins, 1997). This technology was recently evaluated for its capacity to screen LAB for their potential to form volatile compounds (Marilley et al., 2004). In this study, a mass spectrometry-based electronic nose allowed the discrimination between strains from the same species of Lactobacillus casei isolated from Gruyere cheeses (Marilley et al., 2004). Although this mass spectrometry-based electronic nose could be used to differentiate bacterial populations from cheese samples and to screen new aroma-producing strains, there is a need for human input by sensory evaluation to assess the nature of the aroma notes generated by the different strains.

Thus, the objective of this study was to screen the aroma generation of Lactococcus lactis strains isolated from different sources for their potential use in starter cheese cultures. To achieve this objective, Lactococcus lactis strains were isolated and characterized. Then, the aroma generated by the strains was evaluated by an electronic nose and sensory analysis.

\section{MATERIALS AND METHODS}

\section{Collection of Samples}

Nine types of vegetables, 5 commercial dairy starter cultures, raw milk Chihuahua cheese, curd, and whey were used for the isolation of Lactococcus lactis. The dairy products were obtained from local cheese makers from Chihuahua, México. Also, samples were collected from udders and skin of 2 healthy cows.

\section{Preparation and Enrichment of the Samples}

Weighed portions $(1 \mathrm{~g})$ of vegetable samples were grounded with $99 \mathrm{~mL}$ of sterile $(10 \% \mathrm{wt} / \mathrm{vol}$ reconstituted) skim milk and incubated at $21^{\circ} \mathrm{C}$ for $24 \mathrm{~h}$. After incubation, serial dilutions with sterile phosphate buffer ( $\mathrm{pH} 7.2)$ were prepared. Weighed portions $(1 \mathrm{~g})$ of cheese, curd, or whey samples were mixed with 99 $\mathrm{mL}$ of sterile phosphate buffer and serial diluted for their plating (Salama et al., 1993). One percent (wt/vol) solutions of lyophilized commercial dairy cultures in sterile skim milk ( $10 \% \mathrm{wt} / \mathrm{vol}$ reconstituted) were incubated at $21^{\circ} \mathrm{C}$ for $12 \mathrm{~h}$ according to the manufacturer's instructions. Udder swabs were first suspended in brain and heart infusion at $10^{\circ} \mathrm{C}$, transferred into sterile skim milk ( $10 \% \mathrm{wt} / \mathrm{vol}$ reconstituted) and incubated at $21^{\circ} \mathrm{C}$ for $24 \mathrm{~h}$ prior to serial dilution in buffer.

\section{Isolation of Lactococci}

Serial dilutions were spread on the surface of M17 agar (Difco Laboratories, Detroit, MI) containing lactose (5 g/L; LM17; Salama et al., 1995). Twenty colonies were picked randomly and subcultured on LM17 for their purification (Corroler et al., 1998). Cultures were tested for Gram and catalase reactions. The gram-positive and catalase-negative cultures were confirmed as elongated ovoid cells by phase-contrast microscopy (Cogan et al., 1997). Cells were frozen and stored at $-20^{\circ} \mathrm{C}$ in LM17 broth containing $40 \%$ glycerol.

\section{Phenotypic Characterization}

The 34 isolates identified as Lactococcus genus were tested for glucose, salicin, and mannitol fermentation. The citrate-fermenting ability was tested with the Kempler and MacKay (1980) medium. Lactose fermentation and protease activity were determined by litmus milk (Difco Laboratories) fermentation and coagulation, respectively (Alonso-Calleja et al., 2002). 


\section{Molecular Identification}

The identification of Lactococcus lactis strains was performed by PCR amplification of the gene $a \mathrm{cmA}$ according to Buist et al. (1995), with the primers PALA4 (5'-CTTCAACAGACAAGTCC-3') and PALA-14 (5'GATAAATGATTCCAAGC-3'; Invitrogen, Carlsbad, CA). The PCR approach for genotypic identification of Lactococcus lactis was carried out by using DNA isolated directly from colonies of each culture previously grown in LM17 agar.

The colonies were suspended in $20 \mu \mathrm{L}$ of double-distilled sterile water and used as template. The PCR mixture contained $1 \mu \mathrm{L}$ of prepared cells; $0.5 \mu M$ each of the 2 primers; $250 \mu M$ (each) of dATP, dGTP, dCTP, and dTTP; $1.25 \mathrm{U}$ of Taq DNA polymerase; $1.5 \mathrm{mM}$ $\mathrm{MgCl}_{2}$; and $5 \mu \mathrm{L}$ of (Tris-HCl and $\mathrm{KCl}$ ) buffer (Invitrogen).

The final volume of reaction was $50 \mu \mathrm{L}$. The PCR amplification was performed with a thermal cycler GeneAmp PCR System 2400 (Perkin-Elmer, Branchburg, NJ). The program consisted of an initial denaturation at $94^{\circ} \mathrm{C}$ for $3 \mathrm{~min}$ followed by 25 cycles. Each cycle consisted of denaturation for $30 \mathrm{~s}$ at $92^{\circ} \mathrm{C}$, primer annealing for $30 \mathrm{~s}$ at $45^{\circ} \mathrm{C}$, and primer extension for $60 \mathrm{~s}$ at $72^{\circ} \mathrm{C}$ (Garde et al., 1999). The PCR products were separated by electrophoresis using (1\%) agarose gels at $80 \mathrm{~V}$ and visualized by staining with ethidium bromide.

\section{Evaluation of the Aroma Profile by an Electronic Nose}

Each of the 23 strains confirmed as Lactococcus lactis was inoculated in M17 broth (Difco Laboratories) containing glucose $(5 \% \mathrm{wt} / \mathrm{vol})$ and incubated $24 \mathrm{~h}$ at $30^{\circ} \mathrm{C}$. After incubation, $100 \mu \mathrm{L}$ of the cellular growth were added to $9.9 \mathrm{~mL}$ of UHT milk. Then, $1 \mathrm{~mL}$ of the inoculated milk was transferred to $20-\mathrm{mL}$ sterile vials and incubated at $30^{\circ} \mathrm{C}$ for $24 \mathrm{~h}$. After incubation time, the samples were stored at $-20^{\circ} \mathrm{C}$ until analysis. This procedure was carried out 3 times for each strain of Lactococcus lactis.

The headspace of the fermented milks were analyzed with an electronic nose (e-nose) sensor array system FOX-3000 (Alpha MOS, Nantes, France) with auto sampler (HS 100, CTC Analytics, Nantes, France), which employs 12 metal oxide semiconductor sensors. Samples were thawed at $4^{\circ} \mathrm{C}$ for $3 \mathrm{~h}$. The e-nose conditions included heating the sample at $60^{\circ} \mathrm{C}$ with agitation at $500 \mathrm{rpm}$ for $600 \mathrm{~s}$ before injection. Then, a 2,500- $\mu \mathrm{L}$ sample was withdrawn from the headspace and injected into the sensor chambers and flushed over the sensors with a flow rate of $150 \mathrm{~mL} / \mathrm{min}$. Data were recorded for $2 \mathrm{~min}$, and the delay between the sample injected and the next injection was $7.5 \mathrm{~min}$. All strains were evaluated individually; additionally, some mixtures of strains isolated from nondairy and commercial starters were also assessed.

\section{Sensory Analysis}

For sensory analysis, inoculated UHT milk was prepared as described for the e-nose. Seven nonsmoking individuals, staff members and students, 4 male and 3 female, 24 to $51 \mathrm{yr}$ of age with previous experience in the evaluation of dairy products, were selected. To generate odor descriptors, the aroma terms were initially identified in a 2-d roundtable discussion with judges. Once terms were generated, 2 common odor descriptors were identified and defined as yogurt-like and Fresco cheese-like. Terms associated with yogurtlike aroma were fermented, whey, and yeasty.

Fresco cheese-like odor was described as the typical aroma of traditional Mexican Fresco cheese produced from raw-milk (Torres-Llanez et al., 2006). Terms associated with Fresco cheese-like odor were dirty sock, barny, cowy, and fecal. After defining odor descriptors, judges were trained with the use of a 9-cm unstructured intensity scale going from 0 (absent) to 9 (very strong). During training, panelists were presented with references. The UHT milk was used to identify the 0 (absent) on the scale, and commercial plain yogurt or Fresco cheese made from raw milk was used to identify the 9 (very strong). The panel received a 40-h training in 1$\mathrm{h}$ sessions with the use of the scale using inoculated UHT milk. For the evaluation of the inoculated milk, 6 samples identified using a 3-digit code were randomly presented. Samples were presented to the panelists for odor evaluation in incubation glass vials at $15^{\circ} \mathrm{C}$. Panelists evaluated samples individually in booths and were asked to smell coffee beans between samples.

\section{Statistical Analysis}

Sensory data were analyzed with NCSS-PASS software, version 2000 (Statistical \& Power Analysis Software, Kaysville, UT). The ANOVA was performed on each odor descriptor evaluated for the 23 inoculated milk samples following a balance incomplete block design, with panelists as repeated measures (Meilgaard et al., 1999). For the sensory data generated in the analysis of milk samples inoculated with selected single strains or strain mixtures, a randomized (complete) block design was used, with panelists as repeated measures (Meilgaard et al., 1999). Also, ANOVA was performed on the e-nose data of one specific e-nose sensor (LY2/gCT) or microbial counts generated by milk samples inoculated with selected single strains or strain 


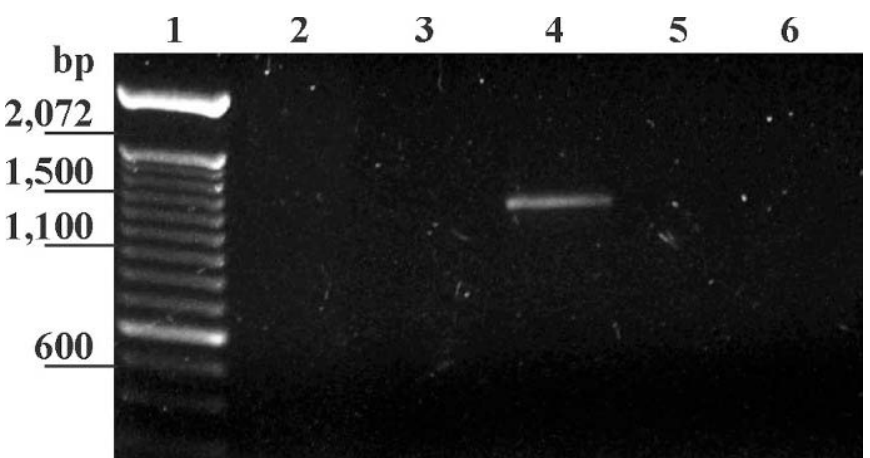

Figure 1. Agarose gel electrophoresis of PCR products formed by acmA gene amplification showing the specificity of primers PALA-4 and PALA-14. Lane $1=100-\mathrm{bp}$ DNA ladder; lane $2=$ Escherichia coli O157:H7 ATCC 43888; lane $3=$ Staphylococcus aureus ATCC6538; lane 4 = Lactococcus strain 21; lane 5 = Listeria monocytogenes ATCC 7644; lane 6 = Salmonella typhimurium ATCC 14028.

mixtures, following a complete randomized design. Where an $F$-test indicated a significant difference between sample means, Tukey paired comparisons were used to determine where the means were different. Significance of differences was defined as $P<0.05$. The data collected by the metal oxide semiconductor sensors were analyzed by principal component analysis (PCA) using a correlation matrix which is part of the software integrated in the e-nose (Alpha MOS).

\section{RESULTS AND DISCUSSION}

\section{Identification of Lactococcus lactis}

All the cultures isolated were confirmed as Gram positive, catalase negative, and coccal-shaped organisms. Based on the ability to ferment different carbohydrates, 34 cultures were tentatively identified as Lactococcus lactis. However, when the amplification of the gene acmA by PCR was performed in each of these cultures, only 23 strains were confirmed as Lactococcus lactis.

According to Garde et al. (1999), both subspecies (Lactococcus lactis ssp. lactis and Lactococcus lactis ssp. cremoris) of Lactococcus lactis contain the same acmA gene that codes for the major peptidoglycan hydrolase in this bacterium. Then, the PCR products obtained with the primers PALA-4 and PALA-14 must result in a fragment of $1,131 \mathrm{bp}$, if the culture tested had the gene acmA (Buist et al., 1995). The specificity of this probe was tested against different bacteria like Escherichia coli, Staphylococcus aureus, Listeria monocytogenes, Salmonella typhimurium, and all were negative in the amplification of the 1,131-bp fragment (Figure 1).

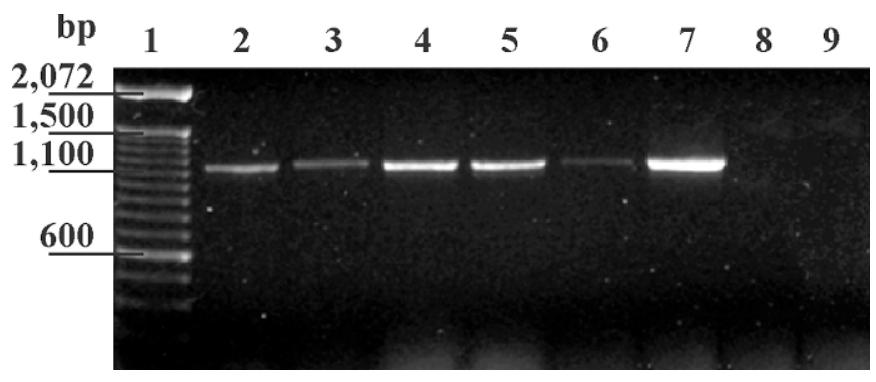

Figure 2. Agarose gel electrophoresis of PCR products formed by acmA gene amplification, with primers PALA-4 and PALA-14 for the identification of Lactococcus lactis. Lane $1=100$-bp DNA ladder; lane $2=$ strain 22 ; lane $3=$ strain 5 ; lane $4=$ strain 20 ; lane $5=$ strain 23 ; lane 6 = strain 11 ; lane 7 = strain 1 ; lane $8=$ Lactobacillus acidophilus 742VD; lane 9 = Lactobacillus casei 163VD.

Moreover, other LAB tested (Lactobacillus acidophilus and Lactobacillus casei) were also negative (Figure 2).

Lactococcus lactis strains were successfully isolated from all dairy products including commercial dairy starters and from some vegetables (Table 1). Spinach, potato, parsley, cabbage, and broccoli samples were not positive for lactococci (Table 1), although lactococci were isolated from these sources by others (Salama et al., 1995). Lactococci isolated from nondairy sources have been reported since 1935 (Stark and Sherman, 1935), and further confirmations have strongly supported the ubiquitous presence of this microorganism in nature (Salama et al., 1993; Klijn et al., 1995; Salama et al., 1995; Corroler et al., 1998).

\section{Technological Characteristics of Isolated Lactococci}

Lactococci isolated from traditional raw-milk products (dairy strains) and commercial dairy starters (industrial strains) showed good proteolytic activity, but the nondairy strains presented very slow (more than $60 \mathrm{~h}$ after their incubation) proteolytic activity (Table 2 ). The lack of proteolytic activity in nondairy strains has been previously reported by Ayad et al. (1999). Similarly, all strains isolated from commercial starters (industrial) and the majority of the lactococci isolated from raw-milk dairy products showed fast lactose fermentation, whereas the nondairy strains showed slow lactose fermentation. These observations were in agreement with those reported by Ayad et al. (2000) who described that nondairy lactococci strains inoculated from milk showed slow acidification activity. Lactose fermentation in Lactococcus lactis is closely related to lactose transport into the cell by a lactose phosphotranspherase system or by a permease (Neves et al., 2005). The lactose-specific components of the phosphotranspherase system as well as cell envelope protein- 
Table 1. Lactococcus lactis strains from nondairy (vegetables), dairy, and industrial (commercial dairy starter cultures) sources

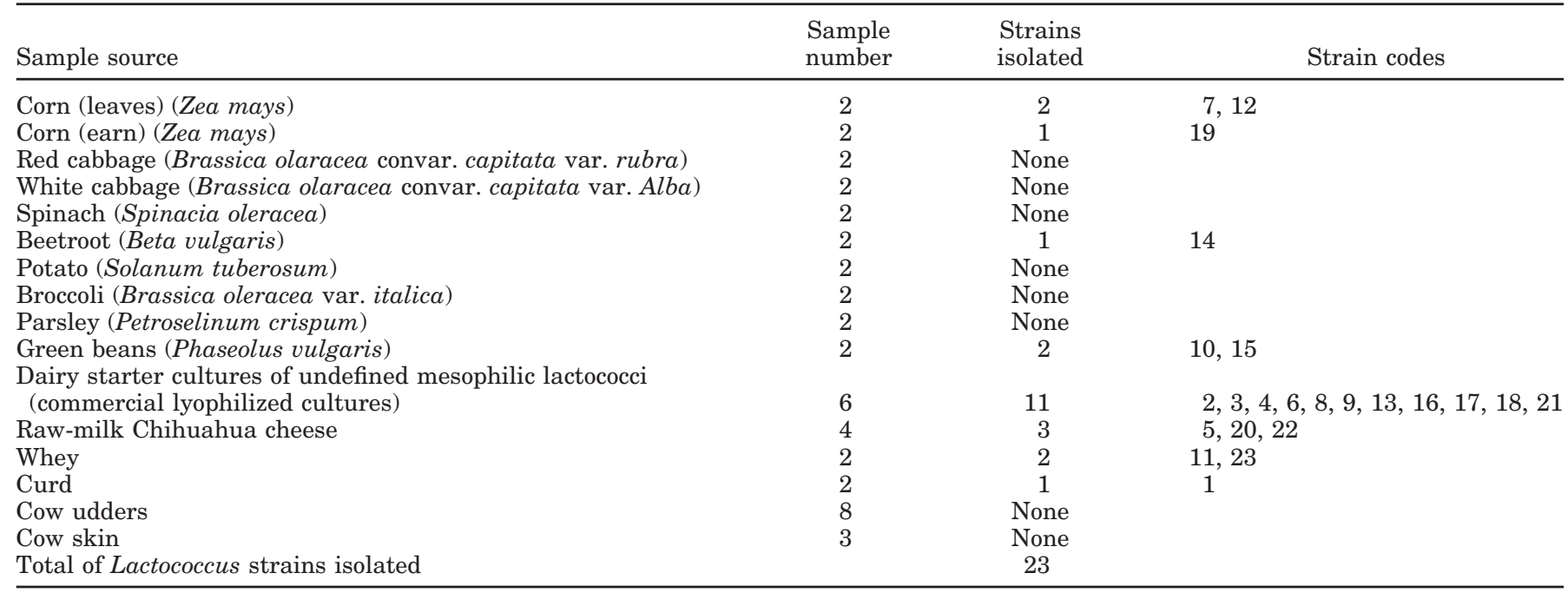

ases are plasmid encoded (O'Sullivan, 2006). Thus, it is possible that lactococci that have been in rich media like milk have acquired the ability to metabolize lactose and casein faster as a survival strategy (Axelsson, 2004).

Citrate fermentation was variable among all the strains, but all nondairy and dairy strains were positive for citrate fermentation. This high percentage of citrate positive strains in nonindustrial lactococci may be related to the biological role of citrate fermentation in the cell. The exchange of divalent anionic citrate and monovalent lactate (citrolactic fermentation) into the cell produce an electrochemical proton gradient across the cell membrane with physiological polarity. But, also, the decarboxylation of oxaloacetate plays an additional role in metabolic energy generation because it consumes a cytoplasmic proton, which results in the generation of a transmembrane $\mathrm{pH}$ gradient (Goupry et al., 2000). These features are important for the survival of bacteria under stress conditions like in nondairy environments. Additionally, citrate fermentation in lactococci is of great industrial importance because it is related to the production of important odor compounds like diacetyl, acetaldehyde, acetoin, and 2,3-butyleneglycol (McSweeney, 2004). However, citrate fermentation in industrial strains isolated from commercial dairy starter cultures was variable with 5 strains from a total of 11 being negative.

\section{Aroma Generation in Milk by Lactococci Strains}

The initial average population of inoculum in the milk was $6.82 \pm 0.36 \mathrm{Log} \mathrm{cfu} / \mathrm{mL}$, and there was no significant difference $(P<0.05)$ among the diverse lacto-

Table 2. Technological characteristics of industrial importance in Lactococcus lactis strains isolated from different natural sources

\begin{tabular}{|c|c|c|c|c|c|c|c|c|}
\hline \multirow[b]{2}{*}{ Strain source } & \multirow{2}{*}{$\begin{array}{l}\text { Number } \\
\text { of strains }\end{array}$} & \multicolumn{2}{|c|}{$\begin{array}{c}\text { Citrate } \\
\text { fermentation }\end{array}$} & \multicolumn{2}{|c|}{$\begin{array}{l}\text { Proteolytic } \\
\text { activity }^{1}\end{array}$} & \multicolumn{3}{|c|}{$\begin{array}{c}\text { Lactose } \\
\text { fermentation }\end{array}$} \\
\hline & & $(+)$ & $(-)$ & $(+)$ & $(-)$ & Fast $^{2}$ & Medium $^{3}$ & Slow \\
\hline Industrial $^{5}$ & 11 & 6 & 5 & 11 & 0 & 11 & 0 & 0 \\
\hline Dairy $^{6}$ & 6 & 6 & 0 & 6 & 0 & 5 & 0 & 1 \\
\hline Nondairy $^{7}$ & 6 & 6 & 0 & $6^{8}$ & 0 & 0 & 1 & 5 \\
\hline
\end{tabular}

${ }^{1}(+)$ : activity; (-): no activity.

${ }^{2}$ Lactose fermentation from 0 to $6 \mathrm{~h}$.

${ }^{3}$ Lactose fermentation from 6 to $12 \mathrm{~h}$.

${ }^{4}$ More than $12 \mathrm{~h}$ for lactose fermentation.

${ }^{5}$ Strains from commercial dairy starter cultures.

${ }^{6}$ Strains from raw milk dairy products.

${ }^{7}$ Strains from vegetables.

${ }^{8}$ Slow (after 48 to $60 \mathrm{~h}$ ) proteolytic activity. 


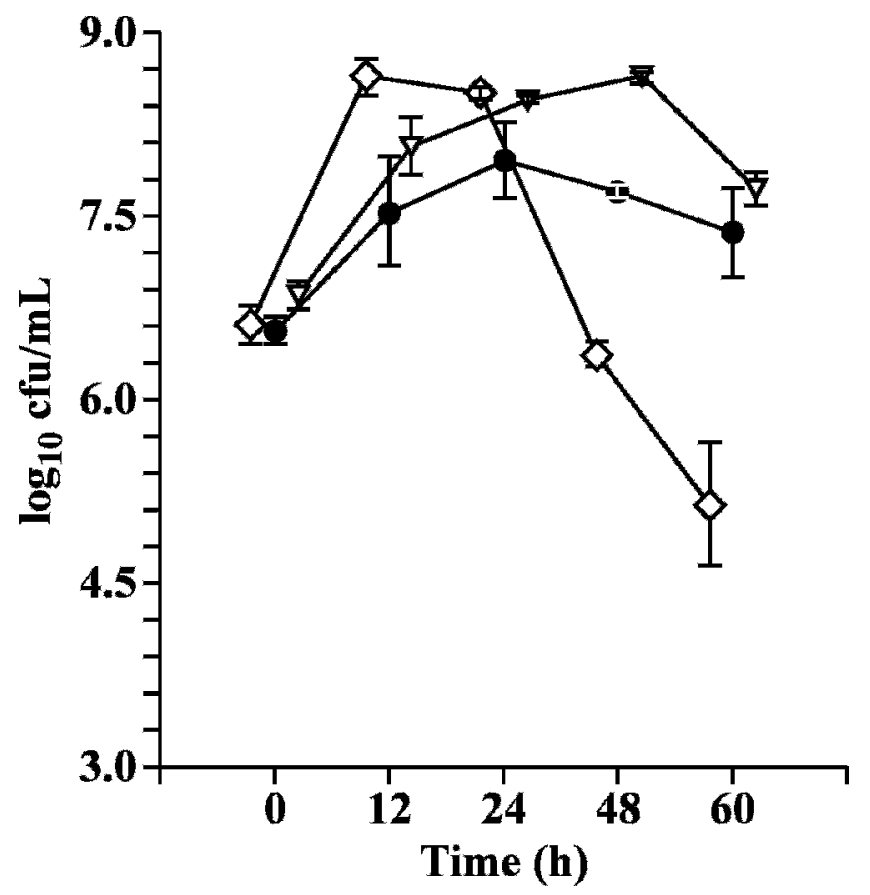

Figure 3. Growth curves of the different strains of Lactococcus lactis in UHT milk at $30^{\circ} \mathrm{C}$ isolated from dairy products $\bullet$, nondairy products $\nabla$, and commercial dairy starter cultures $\diamond$.

cocci strains (Figure 3). Also, the average population in the milk after 24 -h growth was not significantly different $(P<0.05)$. Thus, milk samples were evaluated after this incubation period.

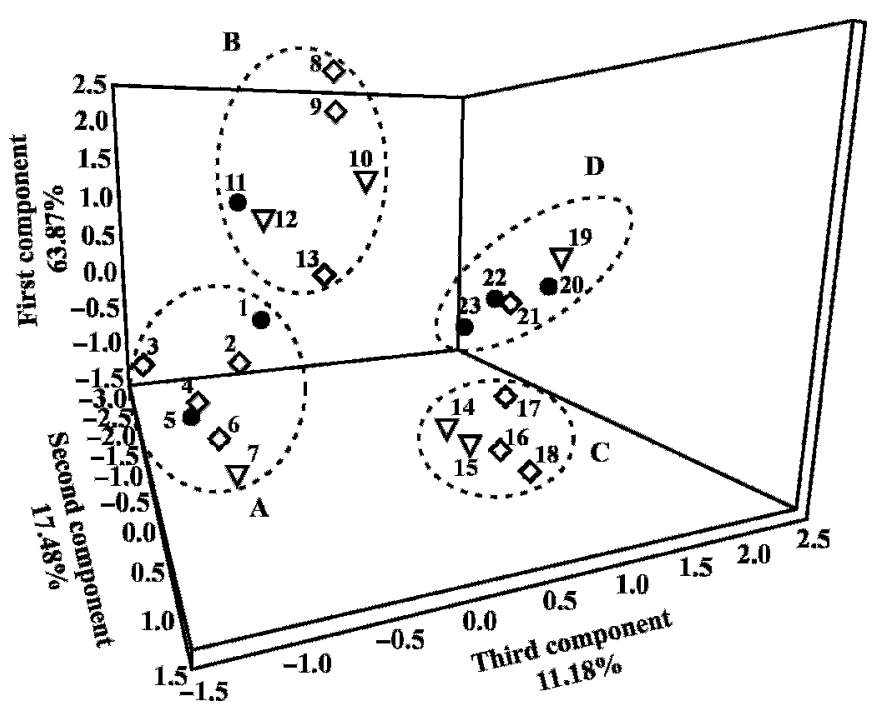

Figure 4. Principal component analysis based on electronic nose data produced by milk inoculated with different strains of Lactococcus lactis isolated from dairy products $\bullet$, nondairy products $\nabla$, and commercial dairy starter cultures $\diamond$. Numbers correspond to strain codes in Table 1.
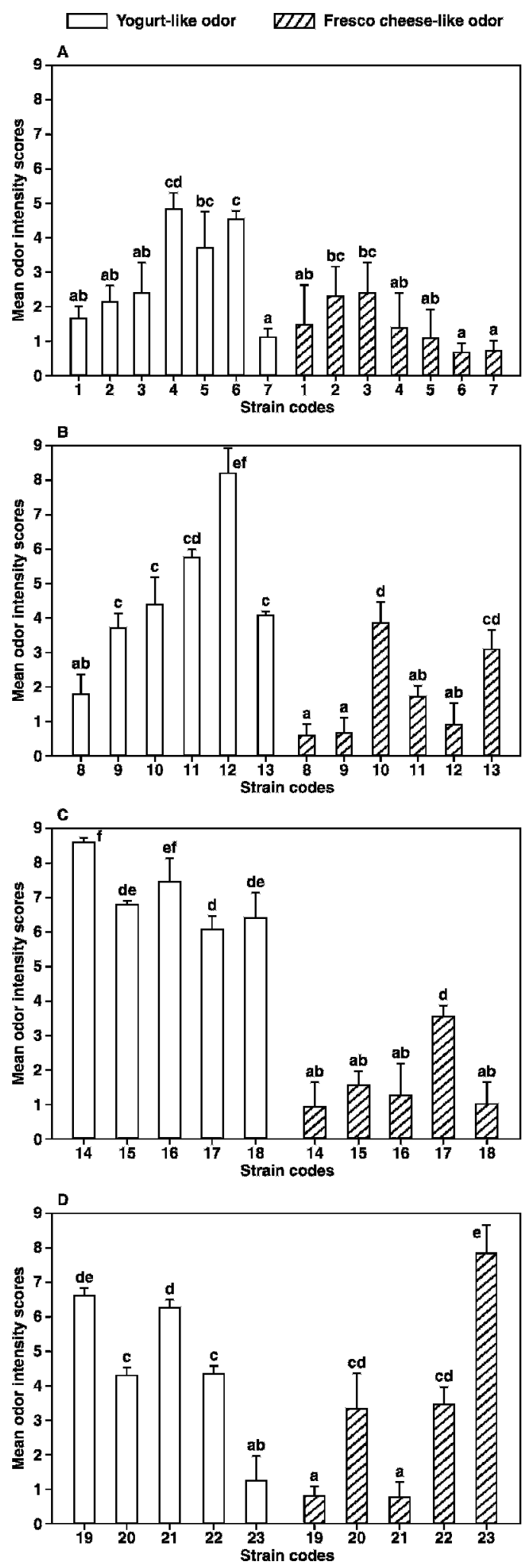

Figure 5. Mean odor intensity scores of milk inoculated with 23 strains of Lactococcus lactis isolated from dairy products, nondairy sources, and commercial dairy starter cultures. Numbers correspond to strain codes in Table 1. ${ }^{a-f}$ Bars with different letters were significantly different $(P<0.05)$ after the Tukey multiple comparison test. 
Table 3. Comparison of aroma generation by specific lactococci strains and their mixtures after their inoculation in milk

\begin{tabular}{|c|c|c|c|c|}
\hline \multirow[b]{2}{*}{ Sample } & \multirow{2}{*}{$\begin{array}{c}\text { Electronic } \\
\text { nose sensor } \\
\text { LY2/gCT }(\mathrm{DR} / \mathrm{R} 0)^{1}\end{array}$} & \multicolumn{2}{|c|}{$\begin{array}{l}\text { Sensory analysis } \\
\text { aroma descriptor }\end{array}$} & \multirow[b]{2}{*}{$\begin{array}{l}\text { Microbial count } \\
\quad(\log \mathrm{cfu} / \mathrm{mL})\end{array}$} \\
\hline & & $\begin{array}{l}\text { Yogurt-like } \\
(\mathrm{cm})\end{array}$ & $\begin{array}{l}\text { Fresco } \\
\text { cheese-like }(\mathrm{cm})\end{array}$ & \\
\hline Milk (control) & $-0.0519 \pm 0.0023^{\mathrm{a}}$ & $\mathrm{ND}^{4}$ & ND & $<10 \mathrm{cfu}$ \\
\hline Strain $14^{5}$ & $-0.1056 \pm 0.0145^{\mathrm{b}}$ & $8.63 \pm 0.15^{\mathrm{a}}$ & $0.83 \pm 1.04^{\mathrm{a}}$ & $7.05 \pm 0.11^{\mathrm{a}}$ \\
\hline Strain $21^{6}$ & $-0.0729 \pm 0.0041^{\mathrm{c}}$ & $6.33 \pm 0.29^{\mathrm{b}}$ & $0.82 \pm 0.49^{\mathrm{a}}$ & $7.13 \pm 0.33^{\mathrm{a}}$ \\
\hline Strain $23^{7}$ & $-0.1138 \pm 0.0048^{\mathrm{b}}$ & $1.13 \pm 1.03^{\mathrm{c}}$ & $8.17 \pm 1.04^{\mathrm{b}}$ & $6.90 \pm 0.32^{\mathrm{a}}$ \\
\hline Strains 14 and 23 & $-0.1320 \pm 0.0122^{\mathrm{d}}$ & $0.57 \pm 0.29^{c}$ & $7.65 \pm 0.68^{b}$ & $6.91 \pm 0.32^{\mathrm{a}}$ \\
\hline Strains 14 and 21 & $-0.1728 \pm 0.0135^{\mathrm{d}}$ & $4.03 \pm 0.45^{\mathrm{d}}$ & $4.24 \pm 0.72^{\mathrm{c}}$ & $6.93 \pm 0.17^{\mathrm{a}}$ \\
\hline Strains 21 and 23 & $-0.1688 \pm 0.0029^{\mathrm{d}}$ & $0.60 \pm 0.26^{\mathrm{c}}$ & $7.50 \pm 1.25^{\mathrm{b}}$ & $6.53 \pm 0.67^{\mathrm{a}}$ \\
\hline \multicolumn{5}{|c|}{$\begin{array}{l}{ }^{a-d} \text { Different superscript letters in the same column were significantly different }(P<0.05) \text { after the Tukey } \\
\text { nultiple comparison test. }\end{array}$} \\
\hline \multicolumn{5}{|c|}{${ }^{1} \mathrm{DR} / \mathrm{R} 0=(\mathrm{R} 0-\mathrm{Rmax}) / \mathrm{R} 0, \mathrm{R}=$ resistance in ohms. } \\
\hline \multicolumn{5}{|c|}{${ }^{2}$ Response of trained judges in an unstructured scale of $9 \mathrm{~cm}$. } \\
\hline \multicolumn{5}{|c|}{${ }^{3} \mathrm{Log} \mathrm{cfu} / \mathrm{mL}$ of UHT milk inoculated with Lactococcus strains; the mixture of strains was approximately } \\
\hline \multicolumn{5}{|c|}{ 50:50. } \\
\hline \multicolumn{5}{|c|}{${ }^{4} \mathrm{ND}=$ not determined. } \\
\hline \multicolumn{5}{|c|}{${ }^{5}$ Lactococcus lactis isolated from beetroot (Beta vulgaris). } \\
\hline \multicolumn{5}{|c|}{${ }^{6}$ Lactococcus lactis isolated from a commercial dairy starter c } \\
\hline
\end{tabular}

The e-nose has a number of sensors; therefore, at a defined point in time any sample will produce an output vector, and for a number of samples an output matrix will be produced. Using PCA, an output matrix is obtained which maximizes the variance across all the samples into principal components. Thus, PCA transforms original dependent variables (e-nose sensor data) into new uncorrelated variables (Hodgins, 1997). In this study, the first 3 principal components that accounted for most of the variation (92.53\%) were plotted for each of the samples determining whether certain samples form groups or whether they were independent. Thus, the evaluation of milk inoculated with different lactococci strains using the e-nose allowed the identification of 4 different groups (A, B, C, and D; Figure 4). These 4 groups generated by PCA showed a clear separation based on differences in their general aroma profile, but not based on the isolation source. All groups presented strains from the different sources, except group $\mathrm{C}$ that did not include strains from dairy products.

To gain some insight into the aroma nature of samples in these 4 different groups generated by the e-nose, sensory data were analyzed by plotting odor intensity scores (Figure 5). Group A showed low intensity of both odor descriptors; strains isolated from commercial dairy starter cultures dominated in this group. On the other hand, groups $\mathrm{B}$ and $\mathrm{C}$ showed more intense yogurtlike odor than group A, particularly strains 12 and 14 isolated from nondairy. In both groups (B and C), strains isolated from nondairy sources and commercial dairy starter cultures dominated because only one strain was from dairy origin (strain 11; Figure 5). Group $\mathrm{D}$, made up of 5 strains, showed the most dispersed data, presenting strains 19 (nondairy) and 21 (commercial dairy starter culture) where yogurt-like odor was the most intense and strain 23 (dairy) where Fresco cheese-like odor was the most intense descriptor. Strains 20 and 22, both from dairy products, presented similar intensities for both descriptors (Figure 5).

In general, lactococci strains isolated from traditional dairy raw-milk products had a tendency to produce both aromas, yogurt-like and Fresco cheese-like (strains 20 and 22), or a strong Fresco cheese-like aroma (strain 23). On the other hand, the majority of lactococci strains from nondairy sources presented a stronger tendency toward the production of intense yogurt-like aroma (strains 12, 14, 15, and 19).

Additionally, specific mixtures combining 2 different lactococci strains were also evaluated to explore a possible aroma potentiation effect. Milk inoculated with mixtures (50:50) containing the same population inoculum of each strain were evaluated (Table 3 ). The mixture of one strain of Lactococcus lactis isolated from beetroot (strain 14) with a strain isolated from a commercial starter culture (strain 21) or with a strain isolated from cheese whey (strain 23) produced a significant change $(P>0.05)$ in the response of the e-nose sensor and the sensory response when compared with the individual strains (Table 3). When milk was inoculated with strains 14 or 21, a high intensity yogurt-like aroma dominated; however, when milk was inoculated with the mixture of both strains (14 and 21), a more balanced 
aroma was generated as it was indicated by the yogurtlike and Fresco cheese-like scores. On the other hand, when milk was inoculated with strains 14 and 23 or strains 21 and 23, a Fresco cheese-like aroma was predominant. These results are in agreement with those reported by Ayad et al. $(2000,2001)$ who reported potentiation of aroma when mixtures of 2 lactococci strains isolated from different sources acted together and attributed this effect to cooperation between their metabolic pathways.

\section{CONCLUSIONS}

The ubiquitous presence of Lactococcus lactis in nature was confirmed with the identification of different strains from nondairy environments. The source of isolation was directly related to some phenotypic characteristics of industrial importance, like lactose fermentation, proteolytic activity, and citrate fermentation. However, there was not a clear relation between the source of isolation and the ability of each strain to produce specific odors. Aroma generation by lactoccoci is determined by the catabolism of amino acids; thus it is possible that strains generating stronger aromas may present more efficient catabolism. Moreover, the limiting factor in the catabolism of amino acids is $\alpha$-ketoglutarate biosynthesis. Therefore, the evaluation of lactococci ability to biosynthesize $\alpha$-ketoglutarate may explain their aroma generation capacity. Studies are presently underway trying to elucidate the metabolic differences among these different lactococci strains.

\section{ACKNOWLEDGMENTS}

This study was supported by the Mexican National Council of Science and Technology (CONACYT) Research Grant No. 42340. Authors N. Gutiérrez-Méndez, B. Vallejo-Cordoba, A. F. González-Córdova, and G. V. Nevárez-Morillón express their gratitude to the Mexican Coca-Cola Co. (Asociación de Embotelladoras Mexicanas de Coca-Cola, A.C.) for granting the $2006 \mathrm{Na}-$ tional Prize on Food Science and Technology for part of this study.

\section{REFERENCES}

Alonso-Calleja, C., J. Carballo, R. Caoita, A. Bernardo, and M. GarcíaLópez. 2002. Comparison of the acidifying activity of Lactococcus lactis subsp. lactis strains isolated from goat's milk and Valdeteja cheese. Lett. Appl. Microbiol. 34:134-138.

Axelsson, L. 2004. Lactic Acid Bacteria: Classification and Physiology. Pages 19-86 in Lactic Acid Bacteria, Microbiological and Functional Aspects. 3rd ed. S. Salminem, A. von Wright, and A. Ouwehand, ed. Marcel Dekker Press, New York, NY.

Ayad, E., A. Verheul, C. de Jong, J. Wouters, and G. Smit. 1999. Flavour forming abilities and amino acid requirements of Lactococcus lactis strains isolated from artisanal and non-dairy origin. Int. Dairy J. 9:725-735.
Ayad, E., A. Verheul, W. Engels, J. Wouters, and G. Smit. 2001. Enhanced flavour formation by combination of selected lactococci from industrial and artisanal origin with focus on completion of metabolic pathway. J. Appl. Microbiol. 90:59-67.

Ayad, E., A. Verheul, J. Wouters, and G. Smit. 2000. Application of wild starter cultures for flavor development in pilot plant cheese making. Int. Dairy J. 10:169-179.

Ayad, E., A. Verheul, J. Wouters, and G. Smit. 2002. Antimicrobialproducing wild lactoccci isolated from artisanal and non-dairy origns. Int. Dairy J. 12:145-150.

Buist, G., J. Kok, K. J. Leenhouts, M. Dabrowska, G. Venema, and A. J. Haandrikman. 1995. Molecular cloning and nucleotide sequence of the gene encodingthe major peptidoglycan hydrolase of Lactococcus lactis, a muramidase needed for cell separation. J. Bacteriol. 177:1554-1563.

Centeno, J. A., A. Cepeda, and J. L. Rodriguez-Otero. 1996. Lactic acid bacteria isolated from Arzúa cows' milk cheese. Int. Dairy J. 6:65-78.

Centeno, A., J. Tomillo, E. Fernández-García, P. Gaya, and M. Nuñez. 2002. Effect of wild strains of Lactococcus lactis on the volatile profile and sensory characteristics of ewe's raw milk cheese. J. Dairy Sci. 85:3164-3172.

Cogan, T., M. Barbosa, E. Beuvier, B. Blanchi-Salvadori, P. Cocooncelli, I. Fernandez, J. Gómez, R. Gómez, G. Kalantzopoulos, A. Ledda, M. Medina, M. Rea, and E. Rodríguez. 1997. Characterization of the lactic acid bacteria in artisanal dairy products. J. Dairy Res. 64:409-421.

Corroler, D., I. Mangin, N. Desmasures, and M. Gueguen. 1998. An ecological study of lactococci isolated from raw milk in the Camembert cheese register designation of origin area. Appl. Environ. Microbiol. 64:4729-4735.

Deisingh, A. K., D. C. Stone, and M. Thompson. 2004. Applications of electronic noses and tongues in food analysis. Int. J. Food Sci. Technol. 39:587-604.

Estepar, J., M. M. Sánchez, L. Alonso, and B. Mayo. 1999. Biochemical and microbiological characterization of artisanal "Peñamellera" cheese: Analysis of its indigenous lactic acid bacteria. Int. Dairy J. 9:737-746.

Garde, S., M. Babin, P. Gaya, M. Nuñez, and M. Medina. 1999. PCR amplification of the gene acmA differentiates Lactococcus lactis subsp. lactis and Lactococcus lactis subsp. cremoris. Appl. Environ. Microbiol. 65:5151-5153.

Goupry, S., T. Croguennec, E. Gentil, and R. J. Robins. 2000. Metabolic flux in glucose/citrate co-fermentation by lactic acid bacteria as measured by isotopic ratio analysis. FEMS Microbiol. Lett. 182:207-211.

Herreros, M. A., R. Arenas, M. H. Sandoval, J. M. Castro, J. M. Fresno, and M. E. Tornadijo. 2007. Effect of addition of native cultures on characteristics of Armada cheese manufactured with pasteurized milk: A preliminary study. Int. Dairy J. 17:328-335.

Herreros, M. A., J. M. Fresno, M. J. Gonzalez Prieto, and M. E. Tornadijo. 2003. Technological characterization of lactic acid bacteria isolated from Armada cheese (a Spanish goats' milk cheese). Int. Dairy J. 13:469-479.

Hodgins, D. 1997 The electronic nose: Sensor array-based instruments that emulate the human nose. Pages 331-371 in Techniques for Analyzing Food Aroma. R. Marsili, ed. Marcel Dekker Inc., New York, NY.

Kempler, G., and L. MacKay. 1980. Improved medium for detection of citrate fermenting Streptococcus lactis subsp. diacetylactis. Appl. Environ. Microbiol. 39:926-927.

Klijn, N., A. Weerkam, and W. de Vos. 1995. Detection and characterization of lactose-utilizing Lactococcus spp. in natural ecosystems. Appl. Environ. Microbiol. 61:788-792.

Law, J., and A. Haandrikman. 1997. Review article: Proteolytic enzymes of lactic acid bacteria. Int. Dairy J. 7:1-11.

Marilley, L., S. Ampuero, T. Zesiger, and M. G. Casey. 2004. Screening of aroma-producing lactic acid bacteria with an electronic nose. Int. Dairy J. 14:849-856.

McSweeney, P. H. 2004. Biochemistry of cheese ripening. Int. J. Dairy Technol. 57:127-143. 
Meilgaard, M., G. V. Civille, and B. T. Carr. 1999. Sensory evaluation technique. 3rd ed. CRC Press, New York, NY.

Neves, A., W. Pool, J. Kok, O. Kuipers, and H. Santos. 2005. Overview on sugar metabolism and its control in Lactococcus lactis: The imput from in vivo NMR. FEMS Microbiol. Rev. 29:531-554.

O'Sullivan, D. 2006. Genetics of dairy starter cultures. Pages 241265 in Food Biotechnology. 2nd ed. K. Shetty, G. Paliyath, A. Pometto, and R. E. Levin, ed. CRC Press, Boca Raton, FL.

Perez-Elortondo, F. J. P., E. P. Aldámiz, M. Albisu, and Y. Barcina. 1998. Indogenous lactic acid in Idiazábal ewes' milk cheese. Int. Dairy J. 8:725-732.

Salama, M., T. Musafija-Jeknic, and S. Giovannoni. 1995. An ecological study of lactic acid bacteria: Isolation of new strains of Lactococcus including Lactococcus lactis subspecies cremoris. J. Dairy Sci. 78:1004-1017.

Salama, M., W. Sandine, and S. Giovannoni. 1993. Isolation of Lactococcus lactis subsp. cremoris from nature by colony hybridization with rRNA probes. Appl. Environ. Microbiol. 59:3941-3945.
Smit, B., W. Engels, M. Alewijn, G. Lommerse, E. Kippersluijs, J. Wouters, and G. Smit. 2004. Chemical conversion of a-keto acids in relation to flavour formation in fermented foods. J. Agric. Food Chem. 52:1263-1268.

Smit, G., B. Smit, and W. Engels. 2005. Flavour formation by lactic acid bacteria and biochemical flavour profiling of cheese products. FEMS Microbiol. Rev. 29:591-610.

Stark, P., and J. Sherman. 1935. Concerning the habitat of Streptococcus lactis. J. Bacteriol. 30:639-646.

Torres-Llanez, M. J., B. Vallejo-Cordoba, M. E. Díaz-Cinco, M. A Mazorra-Manzano, and A. F. González-Córdova. 2006. Characterization of the natural microflora of artisanal Mexican Fresco cheese. Food Contr. 17:683-690.

Van Kranenburg, R., M. Kleerebezem, J. Van Hylckama, B. Ursing, J. Boekhorst, B. Smit, E. Ayad, G. Smit, and R. Siezen. 2002 Flavor formation from amino acids by lactic bacteria: Predictions from genome sequence analysis. Int. Dairy J. 12:111-121.

Yvon, M., and L. Rijnen. 2001. Cheese flavour formation by amino acid catabolism. Int. Dairy J. 11:185-201. 